\title{
Searching for a New Identity in a Rapidly Transforming Urban Landscape
}

\author{
Harry Den Hartog \\ College of Architecture and Urban Planning, Tongji University, Shanghai, China \\ Email: harry.den.hartog@urbanlanguage.org
}

\begin{abstract}
This paper gives a critical view on the incredible growth of Shanghai since the millennium. It focuses on the search for a new identity by this metropolis, both in its new town development as well as on the transformation and regeneration of downtown areas. By explaining the most important planning policies and trends with the help of recent key projects, and analysing how these projects developed over time, the context and challenges of Shanghai's rapid urban transformation become clearer. Especially the challenges for urban preservation and quest for an identity in this continuously changing urban landscape will become more insightful. Based on these insights recommendations are given on how Shanghai can be exemplary, within China and internationally in terms of urban development, urban regeneration, and becoming a more future-proof city. The paper concludes with some trends and future perspectives.
\end{abstract}

KEYWORDS identity, Shanghai, transformation, urban fabric, urban regeneration

Received April 6, 2017; accepted May 31, 2017.

\section{The Cause of Generic Urban Development and the Loss of Identity}

How to maintain identity in a period of drift construction and demolition? Since the 1980s, Shanghai has grown at an unprecedented scale and speed. Each year the diameter of this magnificent city has increased in length by an average of $1 \mathrm{~km}$ and it continues expanding outward like a sphere (Zheng 2010). Much of its land use has changed completely and on average more than 50,000 housesaccording to Shanghai's Statistical Yearbook-have been demolished annually during the first decade of this millennium to make place for new high-rises. One of several collateral effects of this tremendous building boom is that most new urban areas still lack any sense of place, history or identity. This is partly the consequence of obsolete or inadequate building codes. Another reason is the callousness of real estate developers and local governments, who often want to save time and effort by reusing standard plans with a minimum of complexity and variation, in the context of an extremely limited production time. The result is production line housing blocks that lack any kind of relationship with their socio-cultural context and an absolute break with their surrounding urban landscape.

The only distinction to be found in the new-laid areas is in skin-deep facades, generally making use of a romantic or neo-classical idiom. The original local cultural, historical and spatial context seems hardly evident. To be true, the same reproduction of a classical idiom has happened before in the West in earlier times. The historic canals in Amsterdam, for example, are lined by an eclectic structure that showcases classic elements copied from Italy. And early last century Venice Beach was built in Los Angeles, imitating (Li 2010) the watercourse of its Italian sample. However, in the Chinese context, this reference to a classic Western idiom looks even more misplaced, because it denies the rich local cultural traditions and craftsmanship in China.

So how did this loss of identity happen? The standard method of urban expansion in China is based on superblocks, i.e. the construction of large-scale spatial units. The biggest problem of these superblocks can be found along the edges between public and private realms. They are usually sharply demarcated by walls or fences, often 
in combination with over-dimensioned infrastructure or natural boundaries, such as water bodies, thereby emphasising separation instead of facilitating integration.

The origin of this superblock approach can be found in the former danwei system. After Mao Zedong came to power in 1949, the Chinese society was reorganised in work-units, the so-called danwei system (Bray 2005), in which state-owned factories or state-farms supplied housing. In spatial terms, this usually translated into standardised residential quarters, or xiaoqus, adjacent to or on the grounds of the farm or factory where the activity of the danwei (workers unit) took place. During the past two decades, Chinese cities underwent a transition from this danwei system into a more market-oriented system following the economic reforms by Deng Xiaoping, which made the link between work and housing units redundant. However, the idea of basic neighbourhood units is still ubiquitous in contemporary Chinese urban planning, though without any functional relation to a common employer. New-style xiaoqus share facilities and maintenance services, sometimes taken care of by volunteers.

Beside the tradition of building neighbourhood units and perhaps an intention to distinguish or even protect oneself against other social classes, these xiaoqus enforce a sense of community. However, the barriers at the edges increase walking distances and make walking and cycling an unpleasant experience. Due to these barriers neighbourhoods function more or less autonomously and exhibit little cohesion with one another. The new urban landscape has become a rather fragmented landscape where urban and rural, rich and poor, and a new variety of social classes coexist seemingly unconnected with each other.

Moreover, as a result of the hukou household registration system-in its current form set up in 1958 in order to control mass urbanisation by fixing a person to either a rural or an urban location (Chan 1999; Cheng 1994; Den Hartog 2014) — as well as a stronger link between personal income level and affiliation to a xiaoqu, spatial and social segregation are on the rise. The fact that urbanisation has come to be regarded as a tool to stimulate economic growth-by facilitating the rise of a new consuming civilised and urbanised middle class-reinforces the distinction between urban and rural even further. Currently, a reform (Chan 2008) of the hukou system is in progress in an attempt to rebalance social and spatial inequalities, also at the neighbourhood level.

Since recently there are some hopeful new initiatives and projects that break with this trend of conveyor-belt urbanism. For example, in 2015 Shanghai initiated a new urban regeneration policy (Zhong 2017) that tends to reuse and enhance existing urban fabrics instead of erasing them, and the new guidelines introduced in 2016 by the State Council's of China to promote smaller blocks (xiao$q u s)$, narrower roads and a dense street networks to improve walkability, the sense of human scale and urban vitality. Although these guidelines are not binding yet more than a few projects follow the recommendations in these guidelines. Additionally, Shanghai's new 2040 Master Plan (issued in 2016) shows a shift from urban expansion with new town development toward urban densification and regeneration of the existing urban core areas.

\section{The Shift from Multi-use Street Life into Reclusive Xiaoqus: a New Chance for Public Life?}

The extremely rapid social and economic changes in contemporary China are perhaps best illustrated by the changing use and appearance of public spaces. Traditionally, the Chinese public street was always an extension of the individual living room or workshop. Because homes were so small in size, people would eat communally, hang up the wash, and work and negotiate on the front sidewalk or the street. This socially rich and colourful public life would appear to be shifting towards semi-public inner terrains, inside xiaoqus or in shopping malls, away from annoying motor traffic. Today's large-scale urban extensions contrast sharply with the finely woven fabric of the traditional Chinese historic cities. As in most modernist planned new towns elsewhere in the world, the scale employed in building the new China is directed towards automobile use above all other means of transportation, while the majority of the Chinese population still has no cars-at most, they own scooters.

However, with the exception of the often hermetically sealed neighbourhoods in the top segment of the housing market, the before mentioned xiaoqu structure offers also a gradual transition between public and private realms. In an increasing number of xiaoqus, the perceived lack of urbanity is being compensated for through the development of rows of shops adjacent to the outer borders of the superblock, along the public street, often under the supervision of the property management of the xiaoqus themselves. Within xiaoqus as well, shops and other semi-commercial facilities that are accessible also to nonresidents are increasingly being realised, such as a sports facilities or kindergarten. These small scale communities form 'villages in the city' in a positive sense (Lu 2006) and they strengthen the functioning of a pleasant communal 
outdoor space. This is one of the efforts of the national government's policy to promote decentralisation and to encourage new style xiaoqus to be resourceful. New freedom leads to creativity, especially in the districts for lower income groups, where many residents take the opportunity to adapt their new living environment to their personal needs. Public greens are used for gardening, while some of the new houses are rebuilt for commercial activities like a small grocery, a hairdresser's salon, a noodle bar or bicycle repair workshop, even on higher floors (Den Hartog 2010). This frequently happens in an informal fashion: in principle any resident is free to open a shop in his/her home without the need for a permit within the non-commercial xiaoqus. As a result within these xiaoqus and along its edges a continuation of the traditional informal street life can be found, especially in relocation areas where all housing units are occupied, and where there seems to be more need for community at the neighbourhood level. In the more luxurious commercial xiaoqus this is often not the case because many properties are used there for speculation and not for habitation, and because of a different lifestyle and status (Den Hartog 2010).

It would thus appear possible to create a pleasant, open urban environment, using a modified xiaoqu as a basis. In view of the present sectorial approaches of semi-private developers, engineers and local governments, this has yet to take place on any meaningful scale. Once all stakeholders-designers, developers, policy makers and future users and others-together start searching for new possibilities, the opportunities for a 'better city and a better life'referring to the slogan of the 2010 Shanghai Expo-could be realised. A worrisome new tendency is that since this year (2017) many of these semi-informal shops along the public street edges of xiaoqus are closed down by the local government due to their alleged unsuitability with the total image of Shanghai as a modern global city.

\section{China's New Urban Class Creates a Demand for New Urban Typologies}

Today, at the height of neoliberalism, more and more cities worldwide seem to break away from the nation state and position themselves as the centre of the world. Due to decentralisation and deregulation policies, local authorities also in China gain more and more power and many of them try to distinguish themselves in competition with other cities by making ambitious iconic projects, such as donut-shaped hotel towers-even though the State Council in the previously mentioned urban planning guidelines (2016) plead for 'no more weird looking architecture'-or huge amphitheatres, within their Five-Year plans, usually without market research for the real need of these projects. To distinguish themselves and attract foreign investment, many Chinese cities are constructing new Central Business Districts surrounded by luxury compounds with all facilities for an affluent and educated new middle class. Less successful people can hardly afford to live here anymore. They are pushed out to suburbs or remote new towns, usually near new industrial areas (Den Hartog 2010), often because of relocation measures since their old neighbourhood has been destroyed to make place for the well-to-do. Historical neighbourhoods are being demolished at an unimaginably large scale to make way for massive developments for a new middle class of white-collar workers, a new group of residents that no longer works on the land or in a factory, but in offices. China is transforming from a wenbao society, i.e. geared to production, into a xiaokang society that is geared to consumption and comfort (Leonard 2008).

As a result of this shift from an industrial based city to a service based city, in most of China's 'old' inner cities new urban typologies are emerging rapidly, such as shopping malls, compounds with skyscrapers, high-end offices, and hotels. Dozens of malls in all shapes and sizes have been built in Shanghai. The latest generation is often built according to the 'HOPSCA' concept (i.e. according to a functional mix of Hotels, Offices, recreation Park, Shopping, Convention centre, and Apartments), each one at least $100,000 \mathrm{~m}^{2}$ in size and mostly on top of a metro station or near a traffic junction. Since there is an oversupply, more and more malls are partially or even completely empty, but the floors for restaurants and food courts are generally well used and quickly generate consumers for shops as well. As a phenomenon, malls are like a miniature society, a simulated reality. Shanghai has already the largest density of shopping malls on earth, and still almost every month another large-scale mall opens in this amazing city. In size, architecture and programmatic content these malls are aiming to surpass each other in an attempt to attract customers. A recent highlight is Global Harbour in Shanghai's Putuo District: it occupies $450,000 \mathrm{~m}^{2}$ and is designed by British architects, with a neoclassical façade and an Italian-Renaissance-styled interior. Interestingly, it uses local Chinese oriented cultural and recreational programmes-such as a traditional book reading room and a local history museum-inside to attract consumers. The use of foreign styles and themes by introducing romantic and picturesque elements is extremely popular amongst developers. It seems to match the demands and dreams of 
the new rich and middle class looking for status and experience, while most of the consumers do not really seem to care about originality or authenticity (Den Hartog 2010).

Malls are a smart commercial method to guide the overall urban transformation of the city into a middle class consumer machine. However, the collateral damage can be a vanishing street life and disappearance of local traditions due to tabula rasa planning. High-rise towers and malls in Shanghai mostly deny any relationship with their urban context, usually resulting in unpleasant public urban spaces. To create a better and open city (Christiaanse 2009), high-rises and malls do need publicly accessible ground floors, like those implemented in Manhattan through zoning tools and building regulations. Their entrances need to relate to existing or new routes and guarantee easy access for pedestrians.

In short, large scale superblocks, malls, skyscrapers and new infrastructures rapidly have replaced the sophisticated urban fabric of the city, transforming Shanghai into an exciting futuristic metropolis. The next sections of this paper will introduce some new typologies, which are from a socio-cultural and spatial perspective promising, and surely have a positive impact on Shanghai's cosmopolitan identity.

\section{A Slowly Reversing Trend-Some Case Studies}

With Shanghai as a forerunner, many Chinese cities are rediscovering the (economic) value of their remaining built heritage (Waldmeir 2013). Besides Shanghai's more or less preserved former concessions, more and more promising samples can be found of preservation and redeveloping that reconnect the new city with its past. An interesting new typology is the creative factory: the reuse of abandoned industrial heritage buildings as factories for 'creative' production. Following the Cultural Revolution, creative professions have been repressed for several decades (Clark 2008). That has been changed rapidly last few years. Not in order to actually restore the damage done by the Cultural Revolution, but mainly as an extra stimulus for the economy, China's central government has since its $12^{\text {th }}$ Five-Year Plan (2011-2015) designated the creative industry as an important pillar of the national economy. Since then, creative clusters have been shooting up like mushrooms. As many cities are currently transforming from industrial-based to service-oriented, they are aiming to attract the xiaozi, i.e. the hippie-style new Chinese bourgeoisie, who are drinking coffee, eating croissants, and reading foreign books.
Following experiments of creative industries that popped up in many Western cities since the late 1990s, also many Chinese cities are aiming for 'urban generators', or 'breeding grounds' in re-used abandoned factory buildings, albeit in an incomparable way (Mahbubani 2008) and adapted with 'Chinese characteristics'. Similar as in Western cities, especially the cheap rents have a great appeal, regardless of their special architectural characteristics. Nevertheless, from a cultural-historic perspective many buildings and sites can be regarded as valuable and can thus be maintained with this new arrangement. Most initiatives come about through cooperation between local governments and property developers.

After 798 in Beijing and M50 in Shanghai, this new trend of creative factories spread over the country, even towards second-tier cities (Chengdu, Suzhou, and etcetera) and even third-tier cities and new towns like Jiading New City. In the case of Shanghai, since the late last century, the widespread and often outdated polluting plants moved from downtown Shanghai to new industrial estates near new towns and even further to other provinces, especially as part of the preparation for the 2010 Expo aimed to clean-up the Central City for a new middle class. As a result, several millions square meters of former industrial sites came available for new functions.

However, often the definition of 'creative' is a broad one: also tourism, sports, toy design and for instance the packaging industry come under this heading. Except for the more successful creative clusters (e.g. Ferguson Lane, M50, and perhaps also Cool Docks), many of these places do not manage to realise their potential and finally have to face the pressure of the market to make way for commercial real estate (e.g. parts of Red Town near Hongqiao Road). Developers use the creative element as a form of branding. Though these 'creative' breeding grounds are a welcome variation, and certainly welcomed by a new coffee drinking middle class, these places usually do not really make any social, economic or even physical connections with their direct urban context. In contemporary China even museums and galleries are used for this purpose, often designed by famous (international) architects, like the China International Practical Exhibition of Architecture (CIPEA) in Nanjing that has been under construction since 2003, but still empty and waiting for users. Yet these cultural enclaves can be seen as promising oases in the urban concrete jungle.

Next to the reuse of industrial buildings, also the reuse of residential blocks in the former concession areas is an emerging trend, although not always for residential 
purposes but for luxury boutiques, coffee houses and galleries. Since the turn of the millennium, an enormous amount of old residential neighbourhoods have been wiped off the map to make place for speculative real estate. Residents are financially compensated and often get a new home in a distant suburb. As a result of increasing concerns and (international) critique on the demolition of the more characteristic residential blocks, especially those of the lilong (i.e. traditional Shanghainese lane houses; $l i$ = house, long $=$ alley) in the former foreign concessions, there have been several attempts to reuse or reinterpret these structures. In Shanghai and its wider region over the last decade a dozen or so interesting urban renewal projects have been realised, a few of which will be briefly elaborated upon.

\section{Case Xintiandi}

A forerunner, but probably not the best example, is Xintiandi (meaning New Heaven and Earth), which has become a favourite model for many developers and local governments elsewhere in China (Luo 2002; He and Wu 2005). Designed in 2003 by American architect Ben Woods, it is an extremely lucrative concept by the real estate development company Shui On Land. To realise this replica of a traditional shikumen (stone gate) lilong complex, approximately 4,500 people were resettled. The neighbourhood was razed to the ground and replaced, brick-by-brick, by fake 'traditional Chinese style' architecture full of luxurious shops, expensive bars and restaurants, catering primarily to the upper middle class and expatriates. For the untrained eye Xintiandi looks historic and authentic at first sight, however, all facades and floor plans are made-up, nothing is original except some reused ornaments. This pedestrian zone has become the main tourist highlight in Shanghai. It is a sanitised version of the original old displaced neighbourhoods (Qin 2013). The concept has been copied in dozens of other Chinese cities, with varying success. Even mixtures with fake European or other foreign architectural styles are no exception. The jargon of real estate developers has since been enriched with the verb 'to Xintiandi', while architecture critics speak sneeringly about Disneyfication (Goldberger 2001). An interesting, almost cynical detail is that the building where the first National Congress of China's Communist Party took place, which is a protected heritage site, is part of Shanghai's Xintiandi development and has now become a pinnacle of extreme market-driven urban development.

\section{Case Tianzifang}

A more positive model is undoubtedly Tianzifang, in sharp contrast with Xintiandi. This is also a shikumen neighbourhood dating from the 1930s. Until a decade ago factory workers of an adjacent candy factory inhabited it. Many of the small houses were divided into even smaller units and sublet to several families. The alleys were used as an extension to the house, to cook, to wash and to chat with neighbours. Not long after the factory closed its doors, the Chinese painter Chen Yifei (Tsai 2008) moved into the empty factory and opened his studio there, charmed by the high ceilings and industrial architecture. Other artists followed. In 2004 the first house in this neighbourhood was leased to a fashion designer who (illegally) transformed it into a gallery (Qing 2007). In 2006, however, it became known that the area would be demolished to make way for a shopping mall and residential towers, after which artists and residents united themselves and wrote a letter of protest to the district government, in which the socio-cultural history of the area was explained (Qing 2007; Shinohara 2009). Although the landuse rights were already bought by a large developer, the city council decided to tolerate the artists' initiatives as an experiment, with a view to the upcoming Expo 2010 that could showcase this to the world. The developer received in return an adjacent piece of land. Since then more houses were transformed into galleries, arts and crafts shops, restaurants and bars. Initially, only the ground floors were used, later also the upper floors. In the early years, there were signs with the message 'no noise please' to avoid that residents would throw buckets of water through an open window on the terraces with visitors. Later on, the operation and maintenance of the neighbourhood was carried out by local residents and funded without any government support or interference. Artists and designers renovated the old houses by themselves. Homes were converted into stores and restaurants while remaining local residents still kept their traditional everyday life. But when in 2007 an article appeared in The New York Times (Yang 2007) the mass 'discovered' this picturesque little neighbourhood, and after the local government designated the project in 2009 as 'Culture Industry Park' (Shinohara 2009), the real estate prices increased drastically, as did the price of beer and other goods. In 2010, the year of the World Expo in Shanghai, almost two-thirds of the 641 original houses were rented out to entrepreneurs, shopkeepers and artists. During an interview, a local resident told me, 'These are small, poor houses without sanitary facilities, the toilet and kitchen are shared with neighbours, but foreign 
tourists find these streets picturesque.' Indeed, it seems that Chinese consumers are more interested in the luxurious acclimatised shopping mall, which was built by the developer on an adjacent plot of land-as compensation for not destroying Tianzifang. The remaining original inhabitants in the narrow alleys of Tianzifang are now themselves a tourist attraction, together with their laundry hung on bamboo poles flapping above the terraces.

Due to this process of gentrification with increasing rents, Chen Yifei and his friends have left, because they could not afford the rents any longer. Also most of the original residents have left, renting out their places to third parties. What remains are a few extremely profitable commercial oriented galleries. Most establishments are operated nowadays by foreigners. So the tangible buildup structure has been kept, but the intangible lifestyle and local culture are gone. Still Tianzifang remains an exceptional example of urban regeneration by a process of selforganisation (Shinohara 2009). The physical structure remained, but the socio-economic function has changed continuously. The residents jointly self-financed the refurbishment of the pavement and the maintenance of public facilities, such as street lighting and additional tables, chairs and parasols for the visiting public. They formed a Shikumen Owners Management Committee for supervision, and jointly made a preservation guideline and series of operating agreements with tenants.

The question arises whether the idea of Tianzifang can be repeated in other neighbourhoods? In several other lilong neighbourhoods, there also have been processes of functional change, restructuring, and gentrification. A modest attempt to repeat the success of Tianzifang was made in Jing'an Villa. This historic neighbourhood used to be the domicile of several famous Shanghainese, such as writer Eileen Chang and also movie directors, doctors and prominent families. During the Cultural Revolution, all of them had to move out, and their homes were partitioned into smaller units and occupied by multiple families. Half a decade ago, the neighbourhood gradually transformed into a playground for an alternative, mainly international oriented scene with trendy coffee bars. Local residents opened several small establishments in their homes, such as a wine tasting bar, a place for cult film screenings, and a studio for alternative clothing design, aiming for a specific target group, being culture-interested educated young Chinese and Western expatriates. However, because of its illegal character - the buildings are meant for living only because of fire regulations-the initiative was repressed. At first, residents resisted and used removable banners hung on the wall, which were quickly removed when inspectors arrive at the entrance of their neighbourhood. Customers were then presented as 'visiting friends'. Also, in this case, the rental prices in the neighbourhood increased due to its 'chic and shabby' character mixed with a sense of history.

\section{Case Qingpu New City}

Analogous to the Central City of Shanghai similar processes of reuse and gentrification happened in many other cities, and even in new towns. Though always initiated by local governments and developers. An interesting case is Qingpu New City, a district in the west of Shanghai near the lakes. In 2002 the then vice head of Qingpu New City, Sun Jiwei, Alumnus of Tongji University's College of Architecture and Urban Planning, set an ambitious new trend. His goal was the create a 'new-style water town', which would respect the regional Jiangnan culture without preserving or imitating the existing buildings, and which would also make room for modern and international influences. Unlike the generic urban landscape of most other new developments around Shanghai, and elsewhere in China for that matter, Sun chose a development programme that respected old traditions and local culture, to keep the identity of the place. Not by conservation or imitation but by stimulating the use of craftsmanship and traditional materials in an innovative contemporary way. Another aim was to develop the town in a sustainable way, with respect for the 'natural shape of the land'. A dozen Chinese architects were invited, such as Atelier Deshaus and Mada s.p.a.m., and modern international influences were mixed with local regional culture in more than a few newly commissioned public buildings and a dozen other projects. The mostly local architects enjoyed a lot of freedom and created some remarkable buildings. Parts of the old town were renovated and restored, sometimes in the vernacular Jiangnan style, and sometimes mixed with modern interpretations. This new blend of architecture should be able to resist bourgeois tendencies to deploy classical elements in a burlesque manner, which is dominant in most other developments around Shanghai. Within the context of the rapid and often mindless developments in China, Qingpu New City can be considered a nursery for promising young Chinese architects, and also an example of integrating old and new, with more respect for Chinese traditions, and more or less a continuation of the historic urban landscape. 


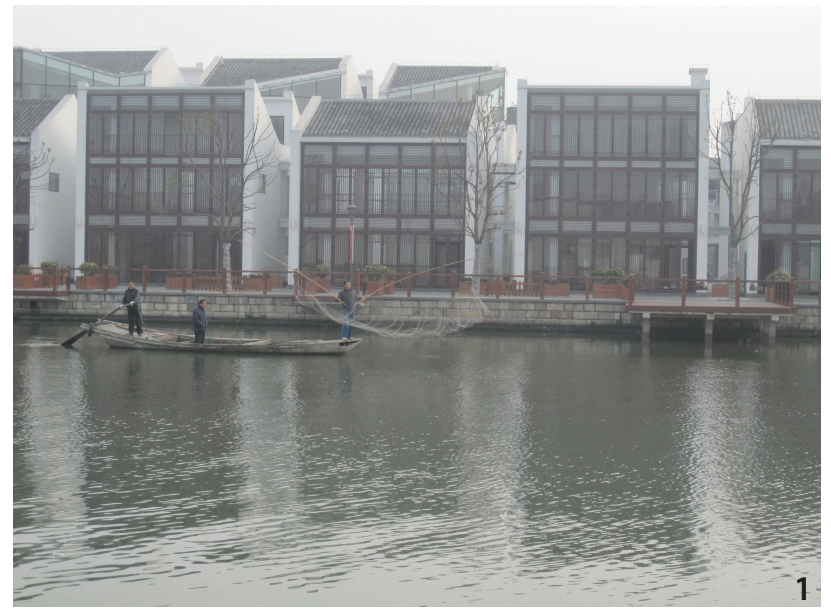

Figure 1 Shangduli's scale and texture are a continuation of the intimacy and atmosphere of the old city, in a modern way without imitating or falsifying history (Source: the author).

\section{Case Shangduli}

A recent case within Qingpu New City can be found in Zhujiajiao, an ancient waterside town that makes part of the new city development. It is here that Chinese architecture practices Atelier FCJZ, Atelier Deshaus and Mada s.p.a.m. have realised the Shangduli Leisure Plaza, a complex consisting of a shopping mall, two hotels and several service flats (Figure 1). The historically sensitive, highprofile site made the plaza important to both the architects and the developer. According to archaeological findings, there was a human settlement on the construction site as many as 5,800 years ago, at the time of the early Songze culture, a matriarchal Chinese Neolithic culture that existed between 3,800-3,300 BC in the Yangtze River Delta.

Zhujiajiao stands out from other waterside towns because it still possesses numerous relatively intact edifices from the Ming and Qing dynasties, as well as infrastructure marked by the Jiangnan characteristics typical of this region: narrow lanes, alleyways, courtyards and locally common materials, colours and architectural details. Over the past ten years, the small town has evolved into a major tourist destination. Its highlight is the Fangsheng Bridge (1571, Ming dynasty), with its five arches the largest in the southern Yangtze Delta and the local equivalent of the Ponte di Rialto in Venice (Italy). Gondolas now ply the canals amid cargo ships. The narrow streets are crowded with day-trippers from Shanghai and, increasingly, with tourists from other provinces or Taiwan, Korea and Japan. Adjacent to the Fangsheng Bridge, Shangduli is an extremely vulnerable spot but also one that presents opportunities. It was a deliberate choice of the Mayor to make this project as a buffer between the old section of
Zhujiajiao and the modern developments right next door. The location was once the cradle of the local food industry, including a factory for the manufacturing of cooking oils and fats. This history was erased from the city's memory in the 1960s with the construction of a cement factory intended for the serial production of concrete housing units. In early 2004 Sun Jiwei asked Mada s.p.a.m. to draw up a schematic master plan with suggestions for a programme, building density and atmosphere. Dividing the area into five parts to be developed by designers from different cultural backgrounds would satisfy the desire for small-scale architecture and for variety. Under the supervision of Mada s.p.a.m., Atelier FCJZ, Atelier Deshaus and Mateo Arquitectura were invited to participate. Shangduli's scale and texture are a continuation of the intimacy and atmosphere of the old city. The architects used subtle modifications to integrate their design into the existing situation. Instead of imitating the ivory walls and indigo tiles' of the old houses, for example, they used darker-and lighter-washed sandstone for exterior walls, which harmonise better with the weathered, grey façades of nearby historic buildings. The lower two metres of these walls are built with a locally sourced brick whose rough texture reinforces the atmosphere of the past.

In all three completed sections of the plan, architects subtly engaged in a visual and morphological analogy that links the newly built to the old city. As often happens in Chinese construction, the client and the design institute, the body responsible for construction drawings, made several modifications to material selection and detailing without consulting the designers. To maintain the integrity of their designs and to provide builders with some direction, the three firms were forced to revise detailed drawings, however without additional payment. Changes in the local political power structure reduced the influence of Mada s.p.a.m. as supervisor, leading the firm to withdraw in 2006. In spite of concessions in material selection and detailing, the main concept nevertheless survived, thanks to broad outlines strategically established at the start of the process, which allowed for some flexibility. In Mada s.p.a.m.'s view, broad outlines are more relevant than details in this kind of project (Den Hartog 2013). The result, within the Chinese context, is still exceptional because of the small-scale atmosphere geared to traditional street life, with pedestrians, handcarts and small shops that open directly to the street. All parking spaces are located below ground level. Solutions for the fire department and emergency services were achieved by skirting rigid construction regulations after long negotiations. The structure of 




Figure 2 Shangduli was supposed to focus on local culinary specialities, but even Starbucks opened recently its doors here, facing the characteristic Fangsheng Bridge (1571, Ming dynasty), the last remaining bridge with five arches in the southern Yangtze Delta (Source: the author).

the old town and that of Shangduli flow almost seamlessly into each other. In spite of all the stumbling blocks, the project has succeeded as an act of resistance against the dominant Chinese trend towards massive projects that usually feature a burlesque classical design language. In the past few years, a process of gentrification has also been initiated in this old town, whereby many original residents are renting or selling their homes or businesses to Shanghai's wealthy middle class. Very few permanently occupied homes remain, and after the sunset, the streets are so deserted and dark that the developer was hesitant to include new housing in the plan. Shangduli was supposed to focus on local culinary specialities, but even Starbucks opened its doors recently here now, facing the Fangsheng Bridge (Figure 2).

\section{Discussion}

Last decade Shanghai_and China in general-faced an unprecedented metamorphosis. The urban lifestyle and urban appearance have changed completely. Although many local families have been able to escape from poverty thanks to China's economic miracle, there is also collateral damage to the environment, liveability, and society as a whole. China's contemporary method of building cities through the use of large-scale superblocks on a tabula rasa have caused an irreversible loss of historical valuable buildings and historic urban landscapes (Van Oers 2012). Existing structures and elements have been wiped out and replaced by shopping malls or standardised superblocks of mass housing, usually built according to outdated planning formulas and unimaginative building codes. The only variation is to be found in the facade, where usually classical elements like arcades and columns are used out of context. Much of the urban patina and layers in time have been lost, as well as the identity and sense of place. The result is that cities all over China seem to become more and more generic, although local conditions could offer so many opportunities to create something more valuable and characteristic. The main cause is that an integrated approach to urban expansion or renewal is largely missing. Short-term planning by developers and local authorities, and a speculative mindset-also by individual consumers-accelerated these problems. A lack of market research coupled with these purely speculative motivations resulted in a huge discrepancy and mismatch between supply and demand, with additionally a lot of empty real estate as a consequence. Especially the outdated building codes made tailor-made solutions nearly impossible. Additionally, there is an accumulation of practical problems, like wrongly chosen building materials, implementation mistakes by low-skilled workers, and an overall lack of maintenance (Den Hartog 2010). More than a few newly built areas lack spatial quality and liveability, even a decade after construction. Another urgent problem is the missing coexistence between different projects or neighbourhoods due to the absence of supervision and long-term planning by planners and decision makers. As a result, large parts of most Chinese cities are transforming rapidly into fragmented urban landscapes with little coherence. 
A city is supposed to be more than a collection of buildings! How to improve the quality of life, and how to maintain a sense of 'home' and 'belonging' - an identity - if the official policy sees urban development mainly as a tool to stimulate economic growth? Private developers seem to enjoy a lot of freedom to build whatever they want, especially since there still is a huge demand. No matter the quality, every house is still sold relatively quickly, in most cases for speculative reasons by families as second or third houses, and as a reserve for their children or retirement benefits. Simultaneously the majority of the new citizens cannot find an affordable home, so they live in dormitories or shared houses. The new affordable housing policy since China's $11^{\text {th }}$ Five-Year Plan (2006-2010) was a first step to urgently search for a new balance between government-driven and market-driven urban development and to supply affordable good quality houses for everybody. Another major reverse policy approach started since the $12^{\text {th }}$ Five-Year Plan (2011-2015) with a more people-oriented approach. Hopefully, this could stimulate local governments towards a more integrated approach to urban development, aimed to create coherent, connected, and open cities. For this reason, smart (bottom-up) initiatives that emphasise a sense of place, like Tianzifang and Jing'an Villa, and perhaps also Shangduli, should be cherished and could serve as inspiration-not to be copied, tailormade approaches are needed for every site-to explore innovative approaches further.

As described above a reversing trend seems on the rise, with a growing number of promising new projects that generate a lot of inspiration. However, also awareness is needed since several of these cases are apparently mainly used for branding or other market-driven purposes. Historical and cultural elements - whatever fakes or real-are happily used to create (artificial) identities and consumer paradises. This apathetic attitude towards architectural appearance and value is illustrated in a symbolic way by a worrisome act: the recent (March 2015) demolition of Wang Shu's Tengtou Pavilion on the former Urban Best Practices Area, built for the 2010 Expo. Wang Shu, winner of the prestigious Pritzker Price in 2012, used recycled materials from demolition sites in this not-unimportant project, likewise in most of his other projects, as a statement against the remorseless demolition, and moreover as a plea for revaluating and enhancing China's rich cultural identity.

Shanghai wants to be a model city and promises, according to its municipality, to show how the city of the future should be shaped. Many innovations in Shanghai are followed or copied whimsically by other Chinese cities. However, much more interesting models for historic preservation nowadays can be found in nearby secondary cities like Yangzhou and Suzhou, and in small towns like Zhujiajiao (as mentioned before). In the Dongquanmen area in Yangzhou for example the historical grown urban fabric has been preserved in a delicate way, with some slight modifications such as renewing the pavement of the streets, removing electric wires and subsidizing the improvement of the houses with new sanitation.

To guarantee the liveability of future cities in China more and better examples are urgently needed, especially in Shanghai. If there is any place in the world with opportunities to make a difference, it should be in China, since it has the political power and financial means to realise amazing projects and set new trends. Most of all it is essential to research the environmental aspects and sociocultural context deeply, since a new balance between market-driven forces and society-driven forces seems inevitable to create more liveable cities. This moment in time should be used to show the world how better cities can be realised: cities which are resilient, robust and simultaneously flexible-thus no blueprint planning but tailor-made solutions-and with a long-term vision, capable of withstanding major environmental, societal and economic challenges.

Based on these principles Shanghai's new identity could become really inspiring and exemplary for other cities, even outside of China. In the context of Shanghai's ambition to become a 'Global City', as written in her latest Master Plan and also in the recent two Five-Year Plans, a radical shift in urban planning practice toward more future-proof solutions would make Shanghai into a real avant-garde and an exemplary metropolis with worldwide importance and impact. New policy trends such as the before mentioned shift to urban regeneration, and the also mentioned new focus on liveability and peoples-centred urban development are the first promising signs.

\section{Acknowledgements}

This paper is an adjusted and updated version of a presentation held by the author during the International Symposium \& Training Course on the Historic Urban Landscape from 7 till 10 December 2014, which was organised by WHITRAP at Tongji University in Shanghai. With special thanks to Ron van Oers (1965-2015), Deputy Director of WHITRAP, who gave many helpful comments while writing this paper. 


\section{References}

Bray, David. 2005. Social Space and Governance in Urban China: The Danwei System from Origins to Reform. Stanford: Stanford University Press.

Chan, Kam, Wing, and Will Buckingham. 2008. "Is China Abolishing the Hukou System?" The China Quarterly (195): 582-606.

Chan, Kam, Wing, and Li Zhang. 1999. “The Hukou System and Rural-Urban Migration in China: Processes and Changes." The China Quarterly (160): 818-855.

Cheng, Tiejun, and Mark Selden. 1994. “The Origins and Social Consequences of China's Hukou System." The China Quarterly (139): 644-668.

Christiaanse, Kees, Tim Rieniets, and Jennifer Sigler. 2009. Open City-Designing Coexistence. Amsterdam: SUN Publishers.

Clark, Paul. 2008. The Chinese Cultural Revolution: A History. Cambridge and New York: Cambridge University Press.

Den Hartog, Harry ed. 2010. Shanghai New Townssearching for Community and Identity in a Sprawling Metropolis. Rotterdam: 010 Publishers.

Den Hartog, Harry. 2013. "Shopping for History." Mark Magazine (43): 164-171. Amsterdam: Frame Publishers.

Den Hartog, Harry. 2014. "China's Hukou System: Attempts to Control Urbanization by Strictly Separating Urban and Rural.” Volume Magazine (39): 102-108.

Goldberger, Paul. 2005. "Shanghai Surprise, The Radical Quaintness of the Xintiandi District." Accessed May 31 2017. http://www.newyorker.com/magazine/2005/12/26/shanghai-surprise

He, Shenjing, and Fulong Wu. 2005. "Property-Led Redevelopment in Post-Reform China: A Case Study of Xintiandi Redevelopment Project in Shanghai." Journal Of Urban Affairs 27(1): 1-23.

Leonard, Mark. 2008. What does China Think? London: Fourth Estate.

Li, Xiangning. 2010. "Heterotopias-Themed Spaces in Shanghai and Los Angeles.” In Shanghai New Towns Searching for Community and Identity in a Sprawling Metropolis, edited by Den Hartog Harry, Rotterdam: 010 Publishers.

Luo, Xiaowei ed. 2002. Shanghai Xintiandi. Nanking: Southeast University.

Lu, Duangfang. 2006. Remaking Chinese Urban Form: Modernity, Scarcity and Space, 1949-2005. London: Routledge.

Mahbubani, Kishore. 2008. The New Asian Hemisphere:
The Irresistible Shift of Global Power to the East. New York: Public Affairs.

Van Oers, Ron, and Francesco Bandarin. 2012. The Historic Urban Landscape: Managing Heritage in an Urban Century. Chichester: Wiley/Blackwell.

Qin, Shao. 2013. Shanghai Gone: Domicide and Defiance in a Chinese Megacity. London: Rowman \& Littlefield.

Shiling, Zheng. 2010. "Preface: Visions on the Urban Development of Shanghai." Shanghai New TownsSearching for Community and Identity in a Sprawling Metropolis, edited by Den Hartog Harry. Rotterdam: 010 Publishers.

Shinohara, Hiroyuki. 2009. "Mutation of Tianzifang - Taikang Road - Shanghai." The New Urban Question: Urbanism Beyond Neo-Liberalism, edited by Rosemann, J. et al. Rotterdam: Papiroz Publishing House.

Tsai, Wan-Lin. 2008. “The Redevelopment and Preservation of Historic Lilong Housing in Shanghai." Accessed July 8 2015. http://repository.upenn.edu/hp_ theses/114

Waldmeir, Patti. 2013. "Shanghai Starts Search for Its Heritage”. Shanghai Financial Times. Accessed July 82015. http://www.ft.com/cms/s/0/56a9ebf2-71d0-11e2-89fb00144f

Yang, Andrew. 2007. "A High-Fashion Lane in Shanghai." Accessed July 8 2015. http://www.nytimes. com/2007/03/04/travel/04surfacing1.html

Zhong, Xiaohua, and Xiangming Chen. 2017. "Demolition, Rehabilitation, and Conservation: Heritage in Shanghai's Urban Regeneration, 1990-2015”. Journal of Architecture and Urbanism 41(2): 82-91. 